Supporting Information

\title{
Current-Induced Metallic State in an Organic Conductor
}

\section{$(\text { EDT-TSF })_{2} \mathrm{GaCl}_{4}$}

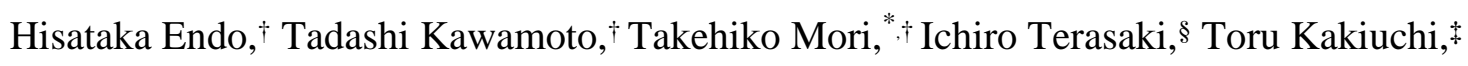

Hiroshi Sawa, ${ }^{\ddagger}, \mathbb{q}$ Mie Kodani, ${ }^{\natural}$ Kazuo Takimiya, ${ }^{,}$and Tetsuo Otsubo ${ }^{£}$

†Department of Organic and Polymeric Materials, Tokyo Institute of Technology, O-okayama 2-12-1, Tokyo 152-8552, Japan, §Department of Applied Physics, Waseda University, Tokyo 169-8555, Japan, ‡The Graduate University for Advanced Studies, Tsukuba, Ibaraki 305-0801, Japan, ๆHigh-Energy and Accelerator Research Organization, Tsukuba, Ibaraki, 305-0801, Japan, and ¿Department of Applied Chemistry, Hiroshima University, Hiroshima 739-8527, Japan

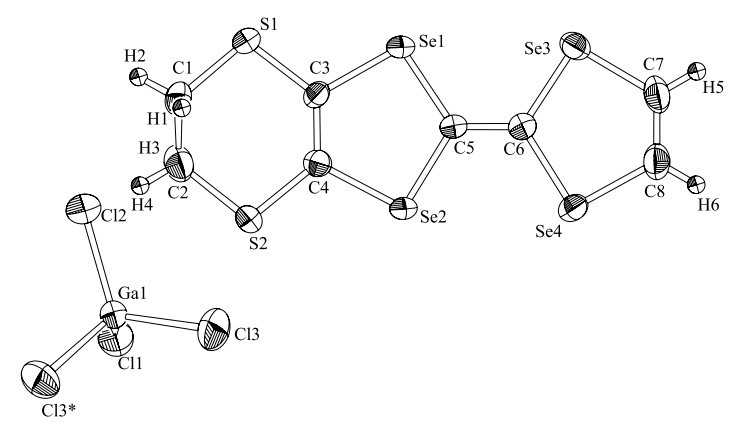

Figure 1S. Ortep view of (EDT-TSF) ${ }_{2} \mathrm{GaCl}_{4}$. 
Table 1S Intermolecular short contacts in (EDT-TSF) $)_{2} \mathrm{GaCl}_{4}$ and (EDT-TSF) ${ }_{2} \mathrm{FeCl}_{4}$. The overlapping modes are depicted in Figure 1b and Figure 4S.

\begin{tabular}{|c|c|c|}
\hline Overlapping mode & Short contacts & \\
\hline \multicolumn{3}{|l|}{$(\mathrm{EDT}-\mathrm{TSF})_{2} \mathrm{GaCl}_{4}$} \\
\hline \multirow[t]{2}{*}{ a1 } & $\mathrm{Se}(1)-\mathrm{Se}(4) 3.831(2) \AA$ & $\operatorname{Se}(2)-\operatorname{Se}(3) 3.824(2) \AA$ \\
\hline & $\mathrm{Se}(4)-\mathrm{S}(1) 4.070(3) \AA$ & \\
\hline $\mathrm{a} 2$ & $\operatorname{Se}(1)-\operatorname{Se}(4) 3.813(2) \AA$ & Se(2)-Se(3) 3.766(2) $\AA$ \\
\hline \multirow[t]{3}{*}{ C } & $\mathrm{Se}(1)-\mathrm{S}(2) 3.536(2) \AA$ & Se(1)-Se(2) 3.8285(8) $\AA$ \\
\hline & $\mathrm{Se}(2)-\mathrm{Se}(3) 3.8242(9) \AA$ & Se(3)-Se(4) 3.8731(9) $\AA$ \\
\hline & $\mathrm{S}(1)-\mathrm{S}(2) 3.569(2) \AA$ & \\
\hline p1 & $\operatorname{Se}(2)-\operatorname{Se}(2) 3.965(2) \AA$ & $\mathrm{Se}(4)-\mathrm{S}(2) 3.910(2) \AA$ \\
\hline p2 & $\mathrm{Se}(1)-\mathrm{Se}(3)$ 3.948(1) $\AA$ & \\
\hline 2 & $\mathrm{Cl}(3)-\mathrm{S}(2) 3.648(3) \AA$ & \\
\hline 4 & $\mathrm{Se}(4)-\mathrm{Cl}(3) 3.674(2) \AA$ & \\
\hline 5 & $\mathrm{Cl}(2)-\mathrm{S}(1) 3.556(2) \AA$ & \\
\hline \multicolumn{3}{|l|}{$(\mathrm{EDT}-\mathrm{TSF})_{2} \mathrm{FeCl}_{4}$} \\
\hline \multirow[t]{2}{*}{ a1 } & $\mathrm{Se}(1)-\mathrm{Se}(4) 3.831(3) \AA$ & $\operatorname{Se}(2)-\operatorname{Se}(3) 3.825(3) \AA$ \\
\hline & $\mathrm{Se}(4)-\mathrm{S}(1) 4.070(3) \AA$ & \\
\hline a2 & $\mathrm{Se}(1)-\mathrm{Se}(4)$ 3.813(3) $\AA$ & $\operatorname{Se}(2)-\operatorname{Se}(3) 3.767(3) \AA$ \\
\hline \multirow[t]{3}{*}{ c } & $\mathrm{Se}(1)-\mathrm{S}(2) 3.536(1) \AA$ & Se(1)-Se(2) 3.8293(6) $\AA$ \\
\hline & Se(2)-Se(3) 3.8198(7) $\AA$ & $\operatorname{Se}(3)-\operatorname{Se}(4) 3.8720(7) \AA$ \\
\hline & $\mathrm{S}(1)-\mathrm{S}(2) 3.583(2) \AA$ & \\
\hline $\mathrm{p} 1$ & Se(2)-Se(2) 3.959(1) $\AA$ & $\mathrm{Se}(4)-\mathrm{S}(2) 3.908(2) \AA$ \\
\hline p2 & $\mathrm{Se}(1)-\mathrm{Se}(3)$ 3.947(1) $\AA$ & \\
\hline 2 & $\mathrm{Cl}(3)-\mathrm{S}(2) 3.646(2) \AA$ & \\
\hline 4 & Se(4)-Cl(3) 3.646(2) $\AA$ & \\
\hline 5 & $\mathrm{Cl}(2)-\mathrm{S}(1) 3.542(1) \AA$ & \\
\hline
\end{tabular}


$a$

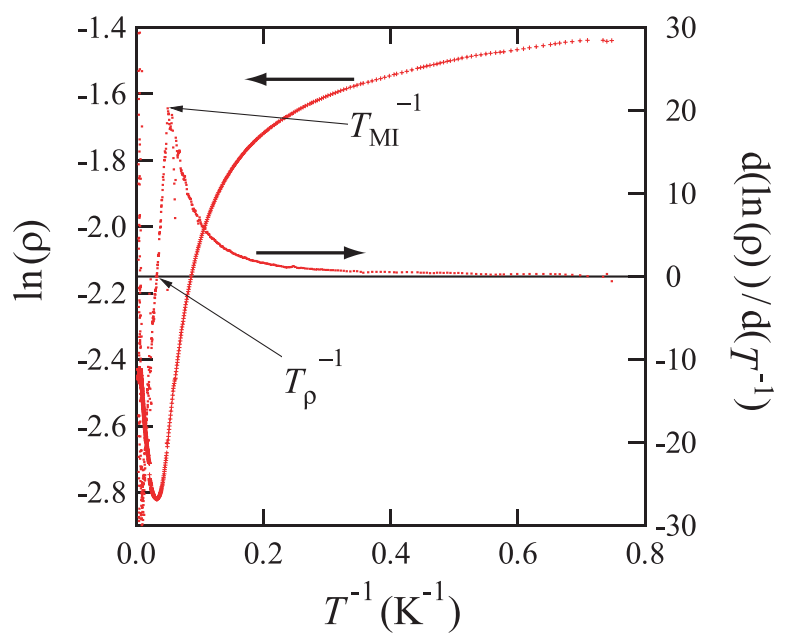

b

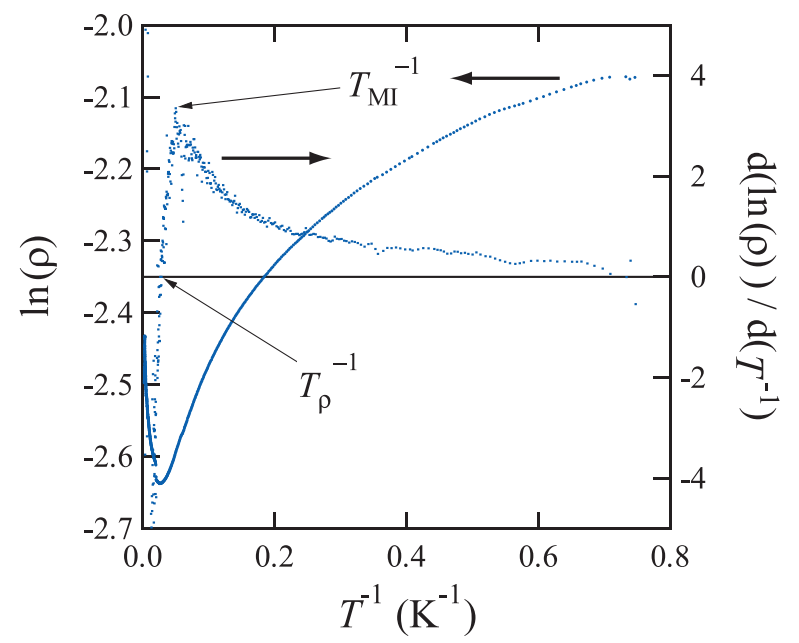

Figure 2S. Arrhenius plots the electrical resistivity of (a) (EDT-TSF) ${ }_{2} \mathrm{GaCl}_{4}$ and (b) (EDT-TSF) ${ }_{2} \mathrm{FeCl}_{4}$. The crystals are elongated along the crystallographic $a(c)$ axis for the $\mathrm{GaCl}_{4}\left(\mathrm{FeCl}_{4}\right)$ salt, and the electrical resistivity is measured along these axes. The minimum of the resistivity $T_{\rho}=30 \mathrm{~K}(35 \mathrm{~K})$, and the MI transition temperature $T_{\mathrm{MI}}=20 \mathrm{~K}(18$ K) are extracted from these plots.

a

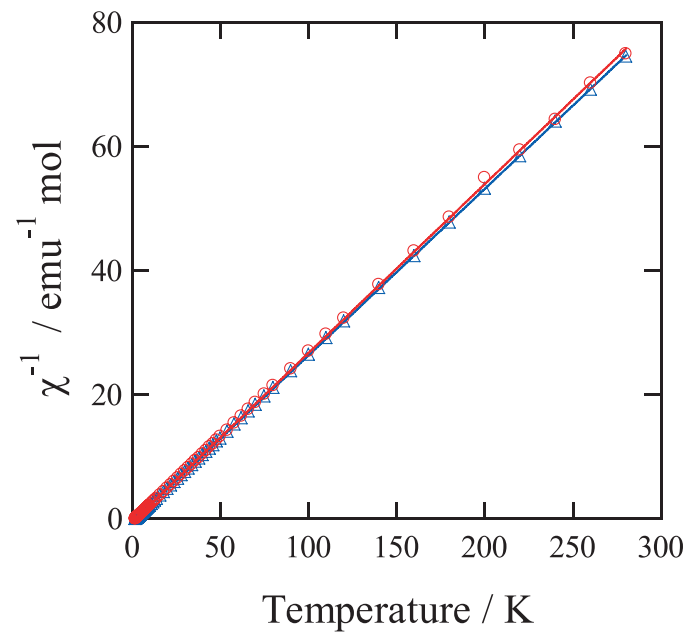

$\boldsymbol{b}$

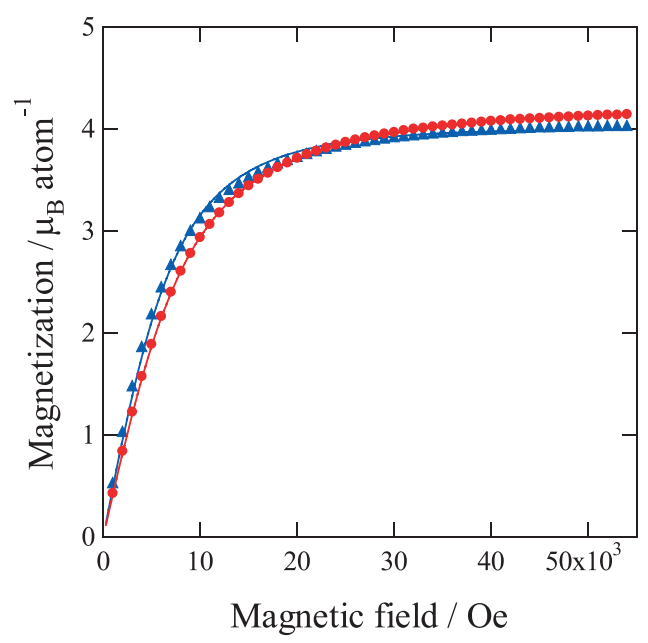

Figure 3S. (a) $\chi^{-1}$ plot of the static magnetic susceptibility of (EDT-TSF) ${ }_{2} \mathrm{FeCl}_{4}$ (blue: $H / / b$; red: $H / / c$ ). The Curie constants are $3.78 \mathrm{emu} \mathrm{K} \mathrm{mol}^{-1}(\mathrm{H} / / \mathrm{b})$ and $3.83 \mathrm{emu} \mathrm{K} \mathrm{mol}^{-1}(\mathrm{H} / / \mathrm{c})$ and the Weiss temperature is $0 \mathrm{~K}$. Magnetization of (EDT-TSF) ${ }_{2} \mathrm{FeCl}_{4}$ at 2K (blue: $\mathrm{H} / / \mathrm{b}$; red: $\mathrm{H} / / \mathrm{c}$ ). 


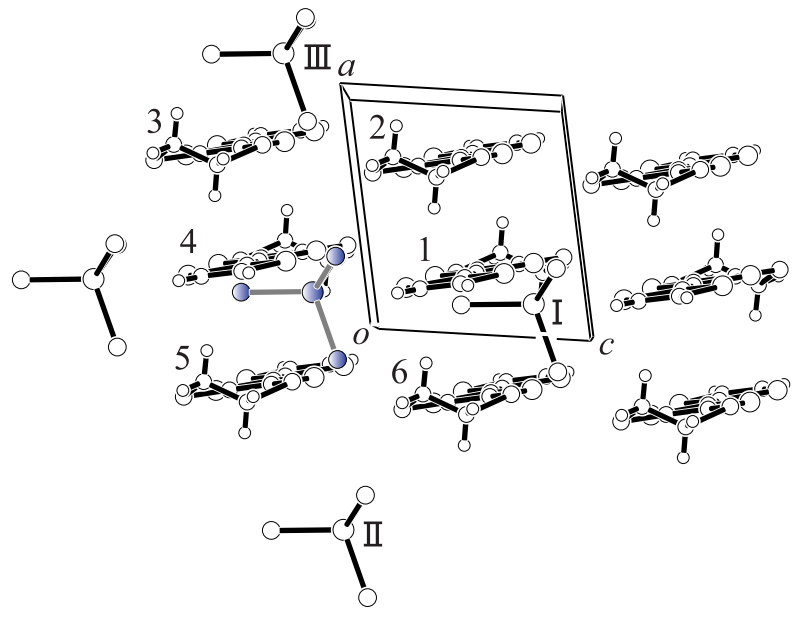

Figure 4S. $\pi \mathrm{d}$ - interaction (1-6) and dd-interactions (I-III) of (EDT-TSF) $\mathrm{FeCl}_{4}$ from the shaded $\mathrm{FeCl}_{4}$ ion. The calculated interactions are listed in Table 2S.

Table 2S. Calculated $\pi \mathrm{d}$ - and dd-overlap integrals $S\left(\times 10^{-3}\right)$ and the magnetic interaction $J$ of $(\mathrm{EDT}-\mathrm{TSF})_{2} \mathrm{FeCl}_{4}$. The interactions are depicted in Figure 4S. The S and Se d orbitals are not included.

\begin{tabular}{ccc}
\hline No. & $S\left(\times 10^{-3}\right)$ & $-J / k_{\mathrm{B}}$ \\
\hline$\pi \mathrm{d}$ & 0.28 & $0.02 \mathrm{~K}$ \\
1 & 0.88 & $0.23 \mathrm{~K}$ \\
3 & 0.27 & $0.02 \mathrm{~K}$ \\
4 & 0.44 & $0.06 \mathrm{~K}$ \\
5 & 1.63 & $0.80 \mathrm{~K}$ \\
6 & 0.09 & $0.002 \mathrm{~K}$ \\
dd & & \\
I & 0.24 & $0.005 \mathrm{~K}$ \\
II & 0.11 & $0.001 \mathrm{~K}$ \\
III & 0.08 & $0.001 \mathrm{~K}$
\end{tabular}

The mean-field sums are $J_{\pi \mathrm{d}}=2 J_{1}+\overline{2 J_{2}+2 J_{3}+2 J_{4}+2 J_{5}+2 J_{6}=2.26 \mathrm{~K} \text { and } J_{\mathrm{dd}}=2 J_{\mathrm{I}}+} J_{\mathrm{II}}+J_{\mathrm{III}}=0.012 \mathrm{~K}$. 


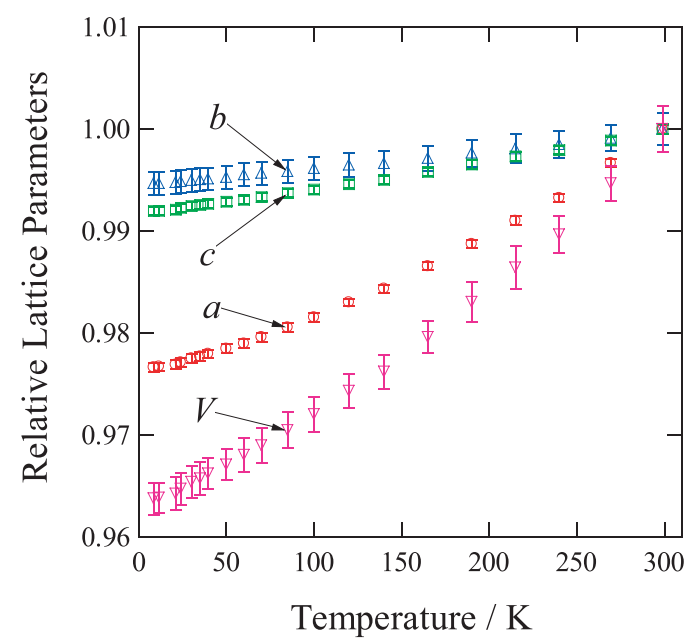

Figure 5S. Temperature dependence of the lattice constants in (EDT-TSF) ${ }_{2} \mathrm{GaCl}_{4}$.

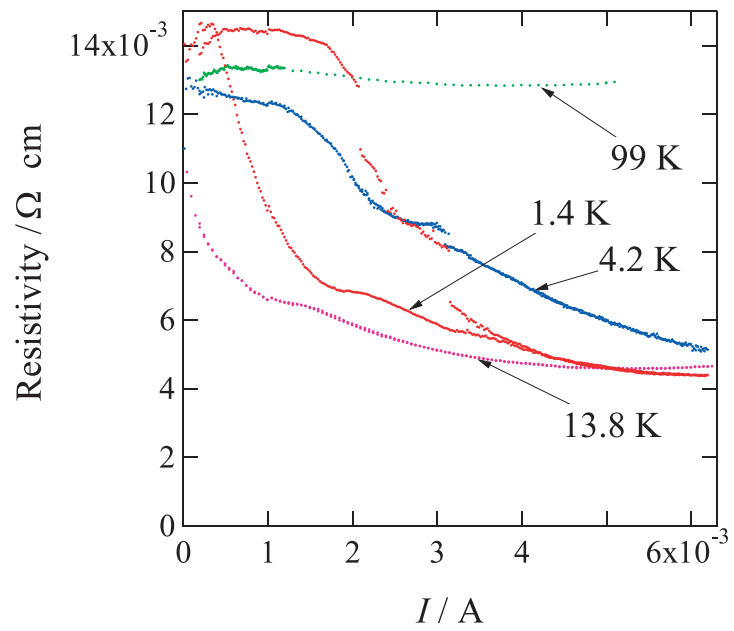

Figure 6S. Current dependence of the resistivity in (EDT-TSF) ${ }_{2} \mathrm{GaCl}_{4}$, measured by the four-probe method. The absence of heating effect is confirmed by the measurements of various pulse lengths. 